\title{
ORIGINAL
}

\section{Characterization of contraction-induced IL-6 up-regulation using contractile C2C12 myotubes}

\author{
Arta Farmawati ${ }^{1 *}$, Yasuo Kitajima ${ }^{1)}$, Taku Nedachi ${ }^{2)}$, Masaaki Sato ${ }^{3)}$, Makoto Kanzaki ${ }^{3), 4)}$ and \\ Ryoichi Nagatomi ${ }^{1), 3)}$ \\ 1) Department of Medicine \& Science in Sports \& Exercise, Graduate School of Medicine, Tohoku University, Sendai 980-8575, \\ Japan \\ 2) Faculty of Life Sciences, Toyo University, Gunma 374-0193, Japan \\ 3) Graduate School of Biomedical Engineering, Tohoku University, Sendai 980-8579, Japan \\ 4) Core Research for Evolutional Science and Technology, Japan Science and Technology Agency (JST), Japan
}

\begin{abstract}
Muscle contractile activity functions as a potent stimulus for acute interleukin (IL)-6 expression in working skeletal muscles. Recently, we established an "in vitro contraction model" using highly-developed contractile C2C12 myotubes by applying electric pulse stimulation (EPS). Herein, we characterize the effects of EPS-evoked contraction on IL-6 expression in contractile C2C12 myotubes. Both secretion and mRNA expression of IL-6 were significantly upregulated by EPS in a frequency-dependent manner in contracting myotubes during a 24-h period, and the response was blunted by cyclosporine A, a calcineurin inhibitor. Longer time $(\sim 12 \mathrm{~h})$ was required for the induction of IL-6 after the initiation of EPS as compared to that of other contraction-inducible CXC chemokines such as CXCL1/KC, which were induced in less than 3 hours. Furthermore, these acute inducible CXC chemokines exhibited no autocrine effect on IL-6 expression. Importantly, contraction-dependent IL-6 up-regulation was markedly suppressed in the presence of high levels of glucose along with increased glycogen accumulations. Experimental manipulation of intracellular glycogen contents by modulating available glucose or pyruvate during a certain EPS period further established the suppressive effect of glycogen accumulations on contraction-induced IL-6 up-regulation, which appeared to be independent of calcineurin activity. We also document that EPS-evoked contractile activity improved insulin-responsiveness in terms of intracellular glycogen accumulations. Taken together, these data provide important insights into the regulation of IL-6 expression in response to contractile activity of muscle cells, which is difficult to examine using in vivo experimental techniques. Our present results thus expand the usefulness of our "in vitro contraction model".
\end{abstract}

Key words: Exercise, Myokine, IL-6, Glycogen, Insulin

IT HAS BECOME increasingly apparent that skeletal muscle functions as an endocrine organ that secretes a number of cytokines, including interleukin (IL)-1 $\beta$, IL-6, IL-8, IL-10, and IL-15 and that physical activity induces some of these muscle-derived myokines, which are therefore referred to as "exercise factors" $[1,2]$. IL-6 expression in muscle is well known to be

Submitted Aug. 23, 2012; Accepted Sep. 6, 2012 as EJ12-0316

Released online in J-STAGE as advance publication Sep. 30, 2012

Correspondence to: Makoto Kanzaki, Ph.D., Graduate School of Biomedical Engineering, Tohoku University, 6-6-11-901/2, Aoba, Aramaki, Aoba-ku, Sendai 980-8579, Japan.

E-mail: kanzaki@bme.tohoku.ac.jp

*A.F., current address: Faculty of Medicine, Gadjah Mada University, Indonesia up-regulated by physical activity, both at the mRNA and the protein level, which is indeed responsible for the increases in the levels of systemic IL-6 concentration after exercise in rodents and human subjects [3-6]. Importantly, IL-6 was shown to have positive effects on skeletal muscle glucose disposal [7, 8], and accumulating evidence demonstrated that some of the beneficial effects of exercise might be mediated by exercise factors including IL-6 [9]. Thus, understanding of the mechanistic details of IL-6 expression in skeletal muscles in response to their contractile activity is an important issue, with health implications especially for patients with type 2 diabetes.

A key issue in understanding the effect of contractile activity on IL-6 up-regulation is to clarify the intracel- 
lular signaling mechanisms by which cells can decipher and respond to a highly complex mechanical stimulus associated with acute energy fluctuations, which is apparently further influenced by environmental circumstances including blood flow and nutrient conditions as well as various humoral factors including autocrine/paracrine factors derived from working skeletal muscles. Indeed, several studies have demonstrated that glucose availability and/or muscle glycogen contents influenced the rate of IL- 6 expression and the release from working skeletal muscle [10-12] and that exercise-induced IL-6 production is significantly augmented under low glycogen conditions in muscle [13, 14]. In addition, several lines of evidence indicated that levels of IL-6 expression in skeletal muscle was modulated by various cytokines including IL- 6 itself $[15,16]$. However, the precise molecular mechanism by which exercise regulates IL-6 expression under diverse nutritional circumstances is poorly understood, which is at least partially due to limitations stemming from the conventional in vivo exercise experiments that make it difficult to precisely control nutritional/ humoral circumstances in vivo.

We recently succeeded in establishing an advanced in vitro muscle exercise model using highly developed $\mathrm{C} 2 \mathrm{C} 12$ myotubes possessing electric pulse stimulation (EPS)-evoked vigorous contractile activity. Importantly, we have observed that these highly developed $\mathrm{C} 2 \mathrm{C} 12$ myotubes displayed some important aspects of beneficial effects of exercise such as improved insulin sensitivity and fiber type switching after EPS-evoked contractile activity [17]. In addition, the contractile $\mathrm{C} 2 \mathrm{C} 12$ myotubes appeared to have the ability to secrete various chemokines/cytokines including IL- 6 and CXCL1/KC in response to EPS $[17,18]$, approximating those observed in working skeletal muscle in vivo [17]. In order to understand exercise-induced IL-6 up-regulation in working skeletal muscles, we took advantage of our in vitro exercise model and investigated the characteristics of IL-6 production from the $\mathrm{C} 2 \mathrm{C} 12$ myotubes in response to EPS-evoked contractile activity in detail. In addition, we attempted to clarify possible influences of CXCL1/ $\mathrm{KC}$, a newly identified myokine, on the EPS-evoked IL-6 expression in contractile myotubes. The effects of ambient glucose levels on IL-6 expression were also investigated.

\section{Materials and Methods}

\section{Materials}

Cell culture equipment was purchased from BD Biosciences (San Jose, CA, USA). Dulbecco's Modified Eagle Medium (DMEM), penicillin/streptomycin and Trypsin-EDTA were purchased from Sigma Chemicals (St. Louis, MO, USA). Calf serum (CS) and fetal bovine serum (FBS) were purchased from BioWest (Nuaille, France). The Western blot detection kit (West super femto detection reagents) was purchased from Thermo Fisher Scientific Inc. (Rockford, IL, USA). Immobilon-P was purchased from Millipore Corp. (Bedford, MA, USA). Bovine serum albumin (BSA) was purchased from Wako (Osaka, Japan). The enzyme-linked Immunosorbent Assay (ELISA) kit for IL-6 was obtained from eBioscience (San Diego, CA, USA). Unless otherwise noted, all chemicals were of the purest grade available from Wako or Sigma Chemicals.

\section{Cell culture}

A mouse skeletal muscle cell line, $\mathrm{C} 2 \mathrm{C} 12$ myoblast [19], was grown on 4-well plates (BD Biosciences) at a density of $0.5 \times 10^{5}$ cells/well in $5 \mathrm{~mL}$ of growth medium. Briefly, $\mathrm{C} 2 \mathrm{C} 12$ myoblasts were culture in the growth medium, DMEM containing $25 \mathrm{mM}$ glucose (high glucose; HG) supplemented with $10 \%$ FBS, $100 \mu \mathrm{g} / \mathrm{mL}$ penicillin, and $100 \mu \mathrm{g} / \mathrm{mL}$ streptomycin, at $37^{\circ} \mathrm{C}$ under a $5 \% \mathrm{CO}_{2}$ atmosphere for 3-4 days until $\sim 80-90 \%$ confluence (day 0). Differentiation was then induced by switching the growth medium to DMEM supplemented with $2 \% \mathrm{CS}, 1 \mathrm{nM}$ insulin, $30 \mu \mathrm{g} / \mathrm{mL}$ penicillin, and $100 \mu \mathrm{g} / \mathrm{mL}$ streptomycin (differentiation medium) [20]. The differentiation medium was changed every 24 hours. The cells were then incubated in DMEM containing $5 \mathrm{mM}$ (low glucose; LG) or 25 $\mathrm{mM}(\mathrm{HG})$ glucose under the indicated conditions.

\section{Electrical pulse stimulation (EPS)}

Five to six days after differentiation, the differentiated $\mathrm{C} 2 \mathrm{C} 12$ myotubes in 4-well plates were placed in a chamber for EPS (C-Dish, IonOptix, Milton, MA). EPS was applied to the cells in the C-Dish using a C-Pace pulse generator (C-Pace 100, IonOptix, Milton MA). The stimulator was set to deliver a pulse with a 2-ms duration, $40 \mathrm{~V} / 60 \mathrm{~mm}$ voltage and 0.1 or $1 \mathrm{~Hz}$ frequency [17]. The cells in the C-Dish were placed inside a humidified incubator at $37^{\circ} \mathrm{C}$ under $5 \% \mathrm{CO}_{2}$ atmosphere. 


\section{ELISA for IL-6 concentration}

Conditioned media were collected at the indicated time point and stored at $-20^{\circ} \mathrm{C}$ until IL- 6 analysis. The concentration of IL- 6 secreted into the culture media was measured using the Mouse Interleukin-6 ELISA Ready-SET-Go! (eBioscience) according to the manufacturer's instructions (detection limit: $4 \mathrm{pg} / \mathrm{mL}$ ). Three or four independent experiments were performed for each experimental condition.

\section{Real-time PCR analysis of gene expression}

Total RNA was prepared using the TRIzol reagent (Invitrogen) and quantitative real-time PCR analysis was performed using the Light Cycler instrument and SYBR Green detection kit (Roche Diagnostics, IN, USA). Primers for IL-6 (mouse IL-6 LightCycler ${ }^{\mathrm{TM}}$ Primer Set, GenBank Accession: NM_031168) were purchased from Nihon Gene Research Laboratories Inc. (Japan). Primers for $\beta$-actin as a control were: 5'-CGT TGA CAT CCG TAA AGA CCT C-3' and 5'-AGC CAC CGA TCC ACA CAG A-3'.

\section{Western blot analysis}

Cells were lysed with lysis buffer $(30 \mathrm{mM}$ Tris $\mathrm{pH}$ 7.4, $100 \mathrm{mM} \mathrm{NaCl}, 1 \mathrm{mM}$ EDTA, 1\% Triton X-100, 2.5 $\mathrm{mM} \mathrm{NaF}, 2 \mathrm{mM}$ NaPP, $1 \mathrm{mM} \mathrm{Na} \mathrm{VO}_{4}, 1 \mathrm{mM}$ PMSF, $10 \mu \mathrm{g} / \mathrm{mL}$ aprotinin, $1 \mu \mathrm{g} / \mathrm{mL}$ pepstatin, $5 \mu \mathrm{g} / \mathrm{mL}$ leupeptin), and protein amount was determined using the bicinchoninic acid assay (BCA; Thermo Fisher Scientific Inc.). The harvested proteins were then subjected to sodium dodecyl sulphate polyacrylamide (10\%) gel electrophoresis (SDS-PAGE) and transferred to a polyvinylidene difluoride (PVDF) membrane (Immobilon-P; Millipore) for Western blot analysis. Immunodetection of each protein was achieved with the primary antibodies (anti-NFAT/c1 and anti- $\beta$-actin antibodies) and horseradish peroxidase-conjugated secondary antibodies, followed by SuperSignal Femto chemiluminescence substrate (Thermo Fisher Scientific Inc.).

\section{Determination of glycogen content}

Cells were lysed with $50 \mu \mathrm{L} /$ well of lysis buffer $(0.6 \%$ perchloric acid and 0.2 M Na-acetate, $\mathrm{pH} 4.8$ ), sonicated (Sonics Vibra Cell) and kept at $-20^{\circ} \mathrm{C}$ until analysis. After addition of $4 \mu \mathrm{L}$ of $1 \mathrm{M} \mathrm{KHCO}_{3}$ and $4 \mu \mathrm{L}$ of $10 \mathrm{mg} /$ $\mathrm{mL}$ amyloglucosidase (Roche), cell lysates $(40 \mu \mathrm{L})$ were incubated at $37^{\circ} \mathrm{C}$ for 2 hours. The lysates were then centrifuged at 15,000 rpm for 10 minutes and the glucose concentration (derived from glycogen) was determined employing a Determiner GLE (Kyowa Medix, Tokyo Japan) with the positive control being $0.1 \mathrm{mg} / \mathrm{mL}$ glycogen (Sigma G-8876, Type III, Rabbit liver). SpectraMax M5 was used with the SoftMAX Pro Windows software program (Molecular Devices, Japan).

\section{Statistical analysis}

All data are presented as means and standard errors of the mean (S.E.). Statistical analysis was performed using Student's paired $t$-test. For analysis of the time course of IL-6 production, a one-way ANOVA was applied to determine significant differences between trials. Statistical significance was accepted at $p<0.05$. Each experiment was repeated at least three times.

\section{Results}

\section{Effects of EPS-evoked contractile activity on the acquisition of IL-6 production}

To investigate the effects of EPS-evoked contraction on the acquisition of IL- 6 production in $\mathrm{C} 2 \mathrm{C} 12$ myocytes, we applied EPS at $40 \mathrm{~V} / 60 \mathrm{~mm}, 2 \mathrm{~ms}$ and $1 \mathrm{~Hz}$ to $\mathrm{C} 2 \mathrm{C} 12$ undifferentiated myoblasts and differentiated myotubes for $24 \mathrm{~h}[17,18]$. LG-DMEM containing 5 $\mathrm{mM}$ glucose was used and conditioned media with or without $24 \mathrm{~h}$ EPS were collected for determining the amount of released IL- 6 by ELISA. As we previously reported [17, 18, 21], vigorous contraction in response to EPS was observed in $\mathrm{C} 2 \mathrm{C} 12$ myotubes, but not in myoblasts (data not shown). In $\mathrm{C} 2 \mathrm{C} 12$ myoblasts, no IL-6 production was observed even after EPS. In contrast, a large amount of IL- 6 was secreted from contractile $\mathrm{C} 2 \mathrm{C} 12$ myotubes exposed to $24 \mathrm{~h}$ of EPS (Fig. 1A), as we previously reported [17]. IL-6 release from myotubes depended on the frequency of EPS, and EPS at $0.1 \mathrm{~Hz}$ resulted in less IL-6 production than that at $1 \mathrm{~Hz}$ (Fig. 1B). The time course of the experiment revealed that the acquisition of IL- 6 production is not acutely induced after short term EPS, but rather requires EPS longer than $12 \mathrm{~h}$ despite the fact that $\mathrm{C} 2 \mathrm{C} 12$ myotubes started to contract after 1-2 $\mathrm{h}$ of EPS, which concomitantly lead to increased secretions of both CXCL1/KC and CXCL5/LIX [18].

To investigate the possibility that CXCL1/KC and CXCL5/LIX, both of which are released in response to EPS-evoked contraction within 1-3 h [18], could mediate and/or influence the acquisition of EPS-induced IL-6 production in this culture system, we examined the effects of SB225002, an antagonist for CXCR2 


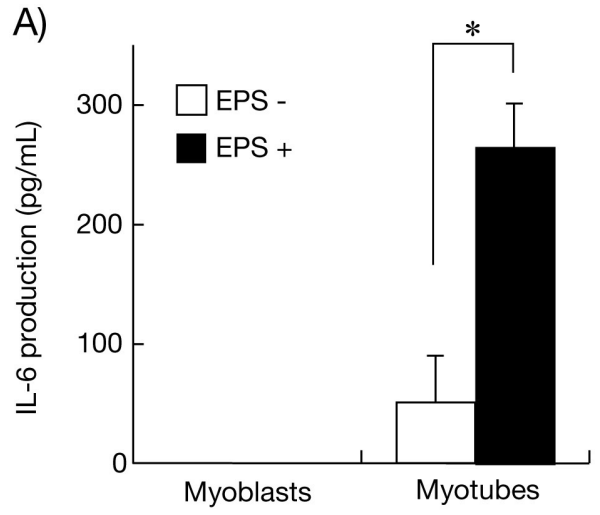

B)

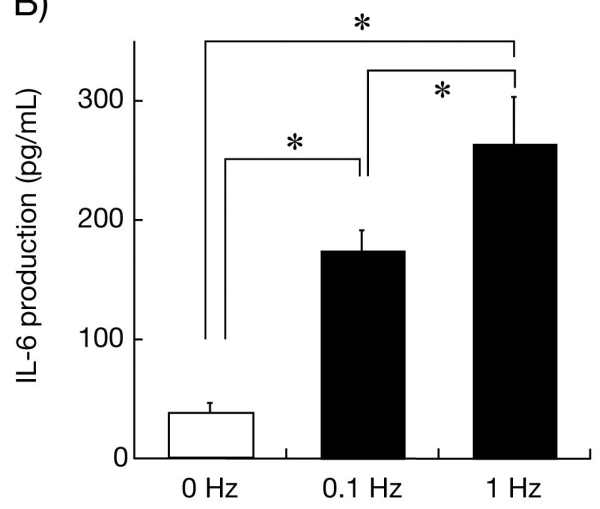

C)

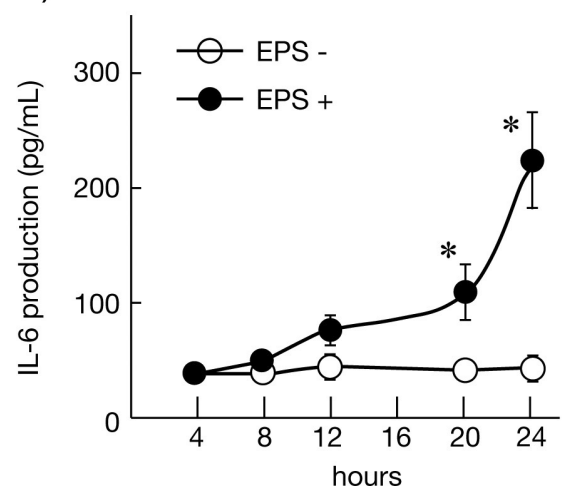

Fig. 1 Characterization of IL-6 production in response to electric pulse stimulation (EPS)-evoked contractile activity

C2C12 myoblasts and $\mathrm{C} 2 \mathrm{C} 12$ myotubes were subjected to EPS $(40 \mathrm{~V} / 60 \mathrm{~mm}, 0.1$ or $1 \mathrm{~Hz}$ frequency, 2-ms duration) for $24 \mathrm{~h}$. DMEM containing $5 \mathrm{mM}$ glucose (LG-DMEM) was used in this experiment. Conditioned medium was collected and subjected to ELISA for measuring IL-6 as described in "Materials and Methods." A: comparison of IL-6 production between myoblasts and myotubes $\mathrm{B}$ : effect of different frequencies of EPS on IL-6 production in $\mathrm{C} 2 \mathrm{C} 12$ myotubes $\mathrm{C}$ : time course of EPS-induced IL-6 production from $\mathrm{C} 2 \mathrm{C} 12$ myotubes At least 3 independent experiments were performed, and values are means $\pm \operatorname{SEM}(* p<0.05)$.
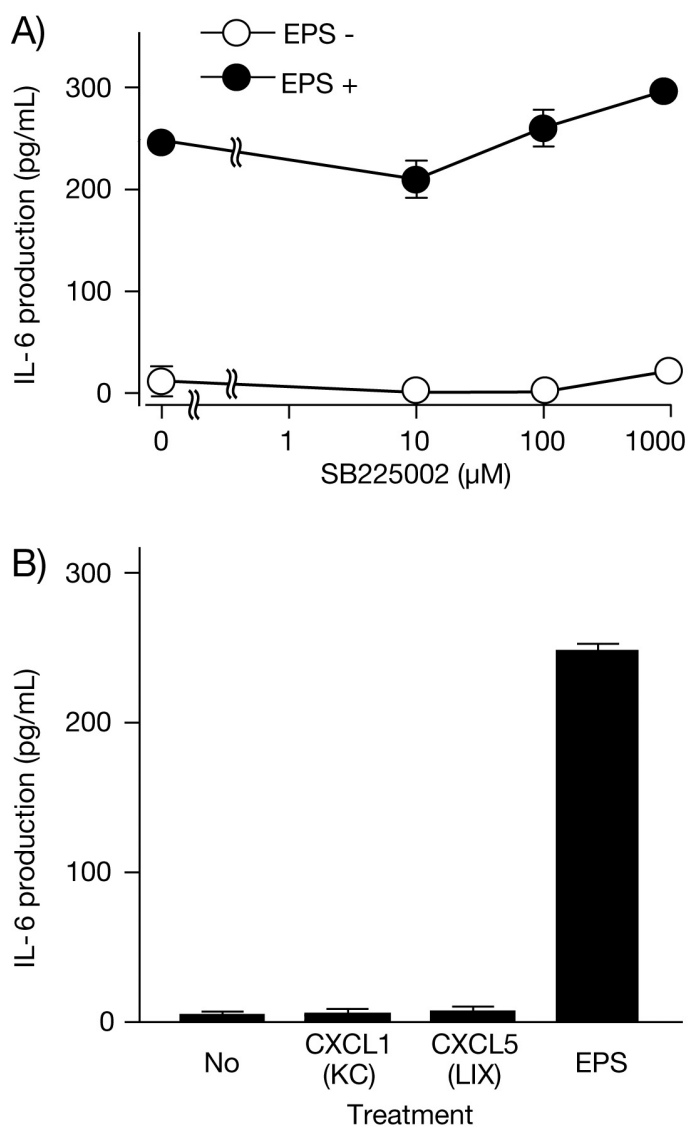

Fig. 2 Effects of contraction-inducible CXC chemokines on EPS-induced IL-6 production

C2C12 myoblasts were treated with EPS ( $40 \mathrm{~V} / 60 \mathrm{~mm}, 0.1$ or $1 \mathrm{~Hz}$ frequency, 2-ms duration) for $24 \mathrm{~h}$ in the absence or presence of the indicated factors. DMEM containing 5 $\mathrm{mM}$ glucose (LG-DMEM) was used in this experiment and conditioned medium was subjected to ELISA. A: effect of CXCR2 antagonist (SB225002) on EPS-induced IL-6 production in $\mathrm{C} 2 \mathrm{C} 12$ myotubes $\mathrm{B}$ : effects of CXCL1/ $\mathrm{KC}$ and CXCL5/LIX on basal IL-6 production during 24 $\mathrm{h}$ incubation At least 3 independent experiments were performed, and values are means \pm SEM.

serving as a common receptor for both $\mathrm{CXCL} 1 / \mathrm{KC}$ and CXCL5/LIX, on EPS-induced IL-6 production (Fig. 2A). Administration of SB225002 during the 24 $\mathrm{h}$ of EPS did not influence IL-6 production, indicating that activation of CXCR2 by these CXC chemokines released from contractile $\mathrm{C} 2 \mathrm{C} 12$ myotubes was not directly involved in the acquisition of IL-6 production elicited by EPS-evoked contraction. Consistent with this observation, exogenous administration of either CXCL1/KC or CXCL5/LIX failed to induce IL-6 production at least during the $24 \mathrm{~h}$ of EPS (Fig. 2B). 
Effects of glucose availability and insulin on EPSinduced IL-6 production and cellular glycogen contents along the course of acquisition of contractility

We next examined the effects of extracellular glucose levels on IL-6 production in response to EPSevoked contraction in C2C12 myotubes. Differentiated $\mathrm{C} 2 \mathrm{C} 12$ myotubes were treated with or without $24 \mathrm{~h}$ EPS in either LG-DMEM or HG-DMEM, and IL-6 production (Fig. 3A), IL-6 mRNA expression (Fig. 3B) and cellular glycogen content (Fig. 3C) were monitored. After $24 \mathrm{~h}$ of EPS-evoked contractile activity, obvious augmentation of IL- 6 release and its mRNA expression was observed; however, under HG conditions these increments were significantly blunted. As expected, cellular glycogen contents were significantly higher in $\mathrm{C} 2 \mathrm{C} 12$ myotubes cultured under $\mathrm{HG}$ conditions than in those cultured under LG conditions (Fig. 3C). Importantly, EPS appeared to be capable of increasing cellular glycogen contents in $\mathrm{C} 2 \mathrm{C} 12$ myotubes, and this effect of EPS was obvious when the myotubes were subjected to EPS under HG conditions (Fig. 3C).

We also examined the effects of insulin $(100 \mathrm{nM})$ during $24 \mathrm{~h}$ of EPS and found that insulin tended to potentiate EPS-induced IL-6 release and mRNA expression, though the increases did not reach statistical significance. Insulin itself had no stimulatory effect on IL-6 production in terms of either protein or mRNA levels. In addition, we found that insulin-induced glycogen accumulation was markedly enhanced in $\mathrm{C} 2 \mathrm{C} 12$ myotubes subjected to $24 \mathrm{~h}$ of EPS-evoked contraction. Taken together, these data demonstrate that EPS-induced IL-6 production is markedly affected by glucose availability (Fig. 3A and B), which in closely associated with cellular glycogen contents (Fig. 3C).

\section{Analysis of intracellular signals involved in IL-6 pro- duction evoked by EPS-induced contraction}

In our previous studies, we demonstrated several intracellular signalling cascades including Erk1/2 and JNK was stimulated by EPS $[17,18]$. To characterize the intracellular signals involved in the up-regulation of IL-6 in response to EPS-induced contraction in $\mathrm{C} 2 \mathrm{C} 12$ myotubes, we utilized various inhibitors that interfere with specific intracellular signalling cascades. As shown in Fig. 4A, cyclosporine A (CsA), an inhibitor of calcineurin, a calcium-activated phosphatase, completely abolished EPS-induced IL-6 release under
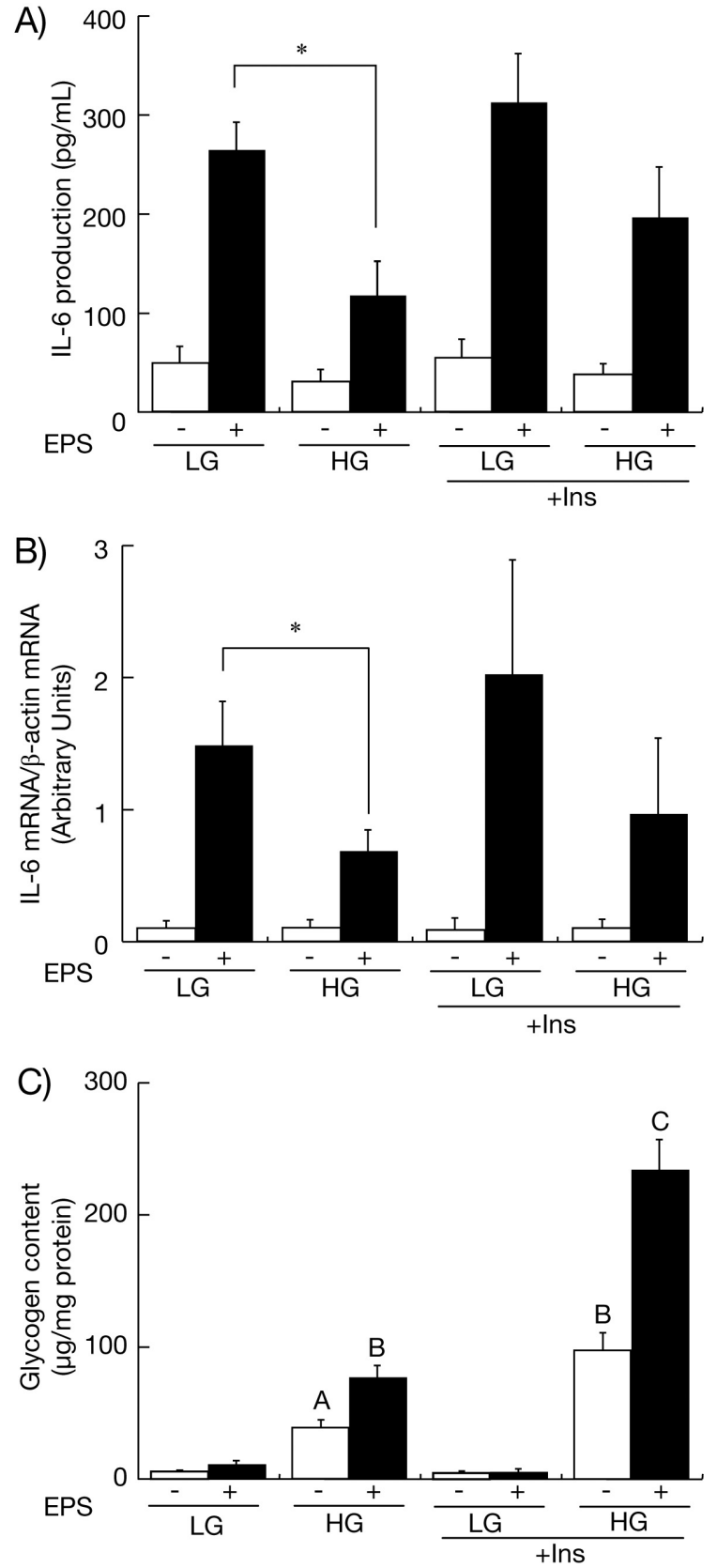

Fig. 3 Effects of extracellular glucose levels on EPS-induced IL-6 production and glycogen accumulation C2C12 myotubes were subjected to EPS (40 V/60 $\mathrm{mm}, 1 \mathrm{~Hz}$ frequency, 2-ms duration) for $24 \mathrm{~h}$ in DMEM containing either $5 \mathrm{mM}$ (LG) or $25 \mathrm{mM}$ (HG) glucose in the absence or presence of $100 \mathrm{nM}$ insulin. A: EPSinduced IL- 6 production was measured by ELISA. B: Levels of IL- 6 and $\beta$-actin (as a control) mRNA expressions were measured by real-time RT-PCR. C: Intracellular glycogen contents were measured after $24 \mathrm{~h}$ of culture under each condition At least 3 independent experiments were performed, and values are presented as means $\pm \operatorname{SEM}(p<0.05, *$ or different letters denote statistically significant differences). 

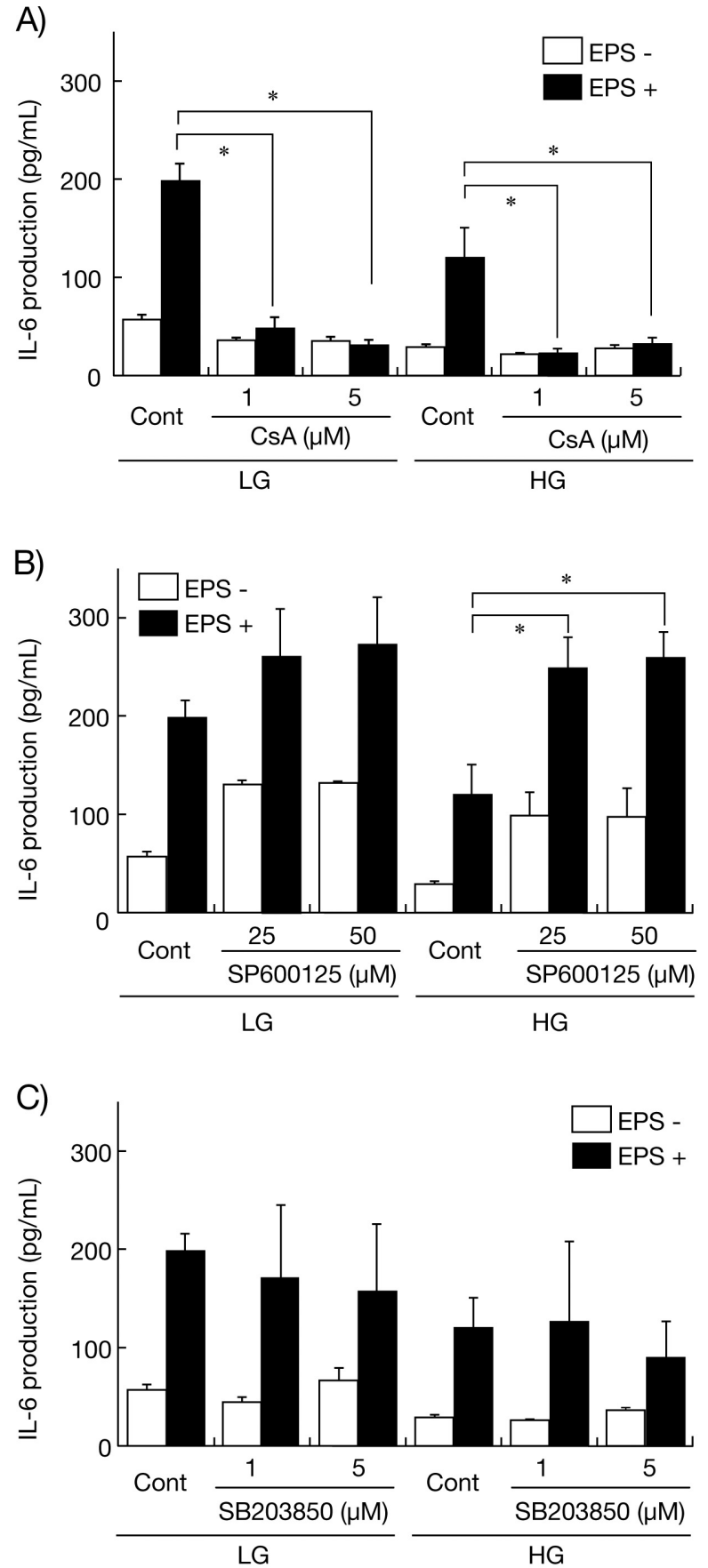

Fig. 4 Effects of cyclosporine A (CsA), SP600125, or SB208350 on EPS-induced IL-6 production

C2C12 myotubes were subjected to EPS ( $40 \mathrm{~V} / 60$ $\mathrm{mm}, 0.1$ or $1 \mathrm{~Hz}$ frequency, 2-ms duration) for $24 \mathrm{~h}$ in DMEM containing either $5 \mathrm{mM}$ (LG) or $25 \mathrm{mM}$ (HG) glucose. EPS-induced IL-6 production, in the presence of the indicated concentrations of CsA (A), SP600125 (B), or SB203580 (C), was measured by ELISA after 24 $\mathrm{h}$ of culture. At least 3 independent experiments were performed, and values are presented as means $\pm \operatorname{SEM}\left({ }^{*} p\right.$ $<0.05)$. both LG and HG conditions. In contrast, a specific inhibitor for JNK, SP600125, did not blunt, but rather increased, EPS-induced IL-6 production (Fig. 4B). No obvious effect of SB203580, an inhibitor of p38 MAP-kinase, on the EPS-induced IL-6 production was observed (Fig. 4C). It should be noted that CsA, but not other inhibitors, showed slight inhibitory effects on the acquisition of contractile activity induced by EPS (data not shown).

\section{Cellular glycogen contents and EPS-induced IL-6 production in C2C12 myotubes}

We further characterized the relationship between cellular glycogen contents and IL-6 expression induced by EPS-evoked contractile activity (Fig. 5). The $\mathrm{C} 2 \mathrm{C} 12$ myotubes that underwent pre-exposure to $20 \mathrm{~h}$ of EPS under LG conditions, allowing them to become competent in terms of IL-6 production in response to EPS (Fig. 1C), were then supplemented with 1, 5 or $22.5 \mathrm{mM}$ of glucose, and the cells were incubated for an additional $4 \mathrm{~h}$ with EPS (Fig. 5A). After $24 \mathrm{~h}(20+$ $4 \mathrm{~h}$ ) in total of EPS, we measured IL-6 mRNA expression levels (Fig. 5A) and cellular glycogen contents (Fig. 5B) to specifically assess the effects of ambient glucose levels during the last $4 \mathrm{~h}$ of EPS. Cellular glycogen levels were very low in $\mathrm{C} 2 \mathrm{C} 12$ myotubes after $24 \mathrm{~h}$ of EPS under continuous LG conditions (with no additions), but administration of glucose significantly increased cellular glycogen levels during the last $4 \mathrm{~h}$ of EPS in a dose-dependent manner (Fig. 5B). Importantly, administration of glucose dose-dependently suppressed the IL-6 mRNA levels elicited by EPS-evoked contraction (Fig 5A). However, administration of pyruvate, a glucose metabolite capable of entering the TCA cycle but which cannot be directly utilized for glycogen synthesis [22], failed to suppress IL-6 mRNA expression (Fig. 5A) with no glycogen accumulation (Fig. 5B).

Although EPS increased dephosphorylation of NFAT/c1 (as assessed by its electrophoretic mobility in SDS-PAGE) (Fig. 5C), a downstream substrate of calcineurin that appears to be involved in the acquisition of EPS-induced IL-6 production (Fig. 3A), administration of either glucose or pyruvate for the last $4 \mathrm{~h}$ of EPS did not reverse the EPS-induced mobility shift of NFAT/c1. Note that administration of CsA significantly suppressed the mobility shift of NFAT/c1. 


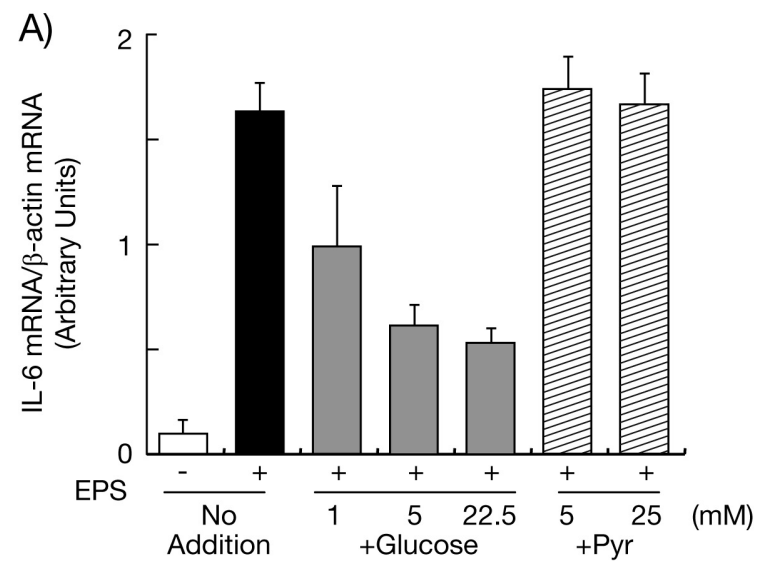

B)

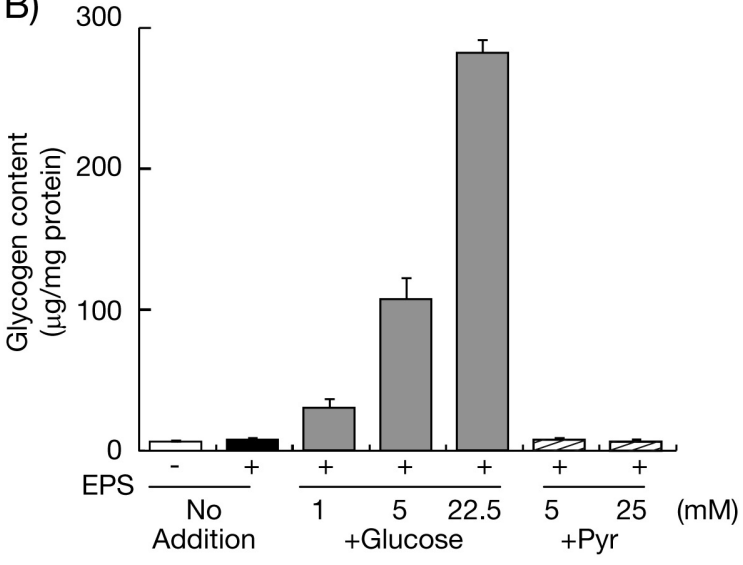

C)

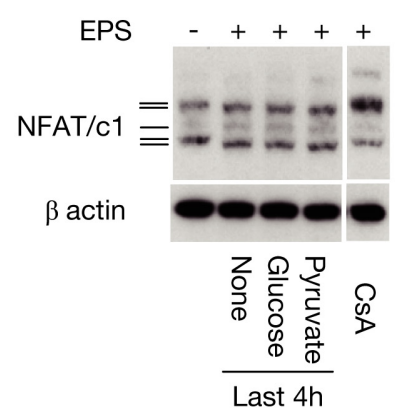

Fig. 5 Effects of glucose supplementation after $20 \mathrm{~h}$ of EPS on IL-6 mRNA expression, glycogen accumulation, and NFAT phosphorylation status

$\mathrm{C} 2 \mathrm{C} 12$ myotubes were treated with EPS for $20 \mathrm{~h}$ in DMEM containing $5 \mathrm{mM}$ glucose (LG) and then the indicated final concentrations of glucose or pyruvate were added to the culture. After an additional $4 \mathrm{~h}$ culture with EPS in the absence or presence of nutrient supplementation, levels of IL-6 and $\beta$-actin (control) mRNA expression (A) and intracellular glycogen contents (B) were measured. Whole cell lysates were subjected to Western blot analysis using anti-NFAT/c1 and anti- $\beta$-actin antibodies (C). At least 3 independent experiments were performed, and values are presented as means \pm SEM.

\section{Discussion}

Because of highly complex interrelated stimuli evoked by muscle contractile activity, physiological responses of working muscle to physical exercise have mainly been assessed using exercising animal models and human subjects $[15,23]$. Recently, we established an advanced in vitro muscle contraction model using cultured myotubes displaying vigorous EPSevoked contractile activity [17, 18, 21]. This model has increasingly been utilized by other researchers for investigating molecular mechanisms underlying various biological responses induced by actual contractile activity of muscle cells [24-27].

In the present study, we observed that acquisition of IL-6 up-regulation in response to EPS-evoked contractile activity was remarkably delayed as compared to the inititation of contraction-inducible CXC chemokines release [18] (Fig. 1), despite the EPS-dependent intracellular $\mathrm{Ca}^{2+}\left(\left[\mathrm{Ca}^{2+}\right]_{\mathrm{i}}\right)$ transients being immediately elicited, leading to acquisition of obvious contractility within $1 \mathrm{~h}$ as well as to increased secretion of these CXC chemokines [17, 21]. Since $30 \mathrm{~min}$ of treadmill running was capable of inducing IL-6 expression in working muscles in rodents $[5,17,26]$, the contractile $\mathrm{C} 2 \mathrm{C} 12$ myotubes apparently require a much longer period of time to acquire the ability to secrete IL-6 in response to contractile activity than do in vivo skeletal muscles. Thus, caution must be exercised in interpreting data obtained from an in vitro exercise model and it is quite difficult to directly compare the results obtained with in vivo data. However, our present study provides several important insights into the regulation of IL-6 expression in response to contractile activity of muscle cells. One of the explanations for the discrepancy between in vivo and this in vitro model is that the acquisition of IL-6 secreting capability may represent the maturation of regenerating muscle fibers.

\section{Contraction-inducible CXC chemokines and EPS- induced IL-6 regulation}

First, it was clearly demonstrated that CXCL1/KC and CXCL5/LIX, both of which began to be secreted from contractile $\mathrm{C} 2 \mathrm{C} 12$ myotubes within approximately $1 \mathrm{~h}$ of EPS [18], did not influence IL-6 expression in this culture system (Fig. 2A and B). These observations establish that the CXC chemokines do not serve as crucial autocrine factors, at least for this event. It is noteworthy, however, that our previous 
report revealed that these contraction-inducible CXC chemokines have autonomous autocrine loops exerting negative feedback on their own secretions [18], and IL-6 reportedly has a positive feedback loop in skeletal muscles [15].

\section{Intracellular signals involved in EPS-induced IL-6 regulation}

Second, pharmacological experiments demonstrated that CsA-sensitive calcineurin activity appears to be essential for the acquisition of IL-6 production during $24 \mathrm{~h}$ of EPS (Fig. 4A). Given that contraction-inducible CXC chemokines were up-regulated via JNK-, but not calcineurin-, mediated signaling cascades [18], expressions of each of these exercise factors appears to be differently regulated at the levels of signaling intermediates upon deciphering the complex contractile activity of muscle cells. In an excellent agreement with our observations, previous reports have indicated involvement of calcineurin activity in exercise-induced IL-6 expression in vivo as well as in ionomycin-induced IL-6 expression in vitro [23, 28, 29]. On the other hand, several lines of evidence have also indicated the involvement of JNK in exercise-induced up-regulation of IL-6 in working skeletal muscle [30] as well as in the EPS-evoked contracting myotubes [26]. Indeed, various stimuli such as lipopolysaccharides, inflammatory cytokines [31-34], reactive oxygen species [35] and epinephrine [36] have also been shown to increase IL-6 expression in skeletal muscle cells, which are mediated at least in part through the activities of JNK and p38 MAP kinase. In fact, we observed in the present study that inhibition of JNK by SP600125 resulted in a slight increase, rather than a decrease, in IL-6 secretion under both basal and EPStreated conditions (Fig. 4B). Furthermore, our previous report revealed that the inhibition of $\mathrm{p} 38 \mathrm{MAP}$ kinase by SB-203580 significantly enhanced JNK phosphorylation [18], possibly due to the regulatory loop acting on the JNK-p38 activation system involving a DUSP family of dual-specificity phosphatases [37]. Thus, our present data using pharmacological inhibitors did not allow us to rule out the possibility that JNK and p38 MAP kinase play a role in the regulation of IL-6 expression in response to EPS-evoked contractile activity in concert with the CsA-sensitive signaling cascade, especially under certain nutritional conditions (as discussed in detail in below).

\section{Intracellular glycogen accumulation and EPS- induced IL-6 regulation}

Third, a striking observation made in the present study is that administration of glucose to maturated contracting myotubes efficiently dampened the IL-6 mRNA expression in a dose-dependent manner along with intracellular glycogen accumulation, whereas pyruvate completely failed to mimic these glucose actions (Fig. 5). While simple cell culture experiments with $24 \mathrm{~h}$ of EPS exposure under HG- and LG-DMEM conditions also indicated possible links among ambient glucose availability, intracellular glycogen contents and EPSinduced IL-6 expression/secretion levels in contractile myotubes (Fig. 3), as shown in previous in vivo studies $[12,14]$, the aforementioned acute nutritional manipulation experiments further support the notion that glycogen accumulation, but not simply energy source supply, is involved in attenuations of contraction-induced IL-6 expression in muscle cells.

Intriguingly, however, delayed administration of glucose failed to reverse the CsA-sensitive EPS-induced mobility shift of NFAT/c1 (Fig. 5C), suggesting that the impacts on IL-6 expression of glucose availability along with intracellular glycogen accumulation are likely mediated through other intracellular signaling pathway(s), rather than the calcineurin-NFAT/c1 signaling cascade, which had a distinct role in the acquisition of contraction induced IL- 6 production. In this regard, a previous in vivo study demonstrated that low pre-exercise intramuscular glycogen content enhanced IL-6 mRNA expression during 60 min of exercise concomitantly with increased nuclear abundance of phosphorylated p38 MAP kinase in human subjects [30], although direct links among these phenomena were not fully investigated. Thus, a future study will be necessary to clarify details of the possible cross-talk between the stress-responsive MAP kinases and calcineurin signaling cascades under intracellular glycogen titrated conditions by manipulating ambient glucose levels as well as the duration of glucose availability and the timing of administration during culture.

\section{Glycogen accumulation and EPS-evoked contractile activity}

Another key observation reported in the present study is the unexpectedly enhanced glycogen accumulations in contracting myotubes during $24 \mathrm{~h}$ of EPS under HG conditions (Fig. 3C). It has been well established employing in vivo studies that intracellular glyco- 
gen contents in working muscles decrease during physical exercise and are eventually depleted by a sufficient amount of exercise [38], even though both enhanced glucose transport mediated via GLUT4 translocation [39] and activation of glycogen synthesis occurred simultaneously $[40,41]$. Given that EPS-evoked contractile activity significantly increased GLUT4 translocation to the cell surfaces of contracting $\mathrm{C} 2 \mathrm{C} 12$ myotubes [17], our present data indicate that glucose uptake is presumably mediated through translocated GLUT4 increased by EPS-evoked contraction, which in turn contributes to the augmented glycogen accumulation. Energy expenditure induced by the EPS-evoked contractile activity burden in the present study $(2 \mathrm{~ms}, 1 \mathrm{~Hz}$, $40 \mathrm{~V} / 60 \mathrm{~mm}$ ) was perhaps insufficient for consuming all incorporated glucose and, as such, surplus glucose was converted into glycogen under HG conditions (25 $\mathrm{mM}$ glucose) even while EPS was persistently applied. On the other hand, as we previously reported, under LG conditions, the extracellular glucose concentration became undetectably low after $\sim 18 \mathrm{~h}$ of culture [42], consequently resulting in a marginal intracellular glycogen content regardless of whether insulin was present (Fig. 3C).

Importantly, we also found that insulin stimulation of glycogen accumulation was further augmented in contracting myotubes under the HG condition with EPS. Although glycogen synthase (GS) is well-known to be activated by dephosphorylation via inactivation/phosphorylation of GS kinase-3 under insulin treatment, a recent report revealed that an allosteric GS activation by glucose-6-phosphate converted from the incorporated glucose through insulin-mediated GLUT4 translocation is the primary mechanism promoting muscle glycogen accumulation in vivo [43]. Thus, increased glycogen accumulations in contracting $\mathrm{C} 2 \mathrm{C} 12$ myotubes in the presence of insulin are very likely to reflect increased glucose uptake mediated through GLUT4 translocation induced by both EPS-evoked contractile activity and insulin [17]. In any case, the present data further strengthen our previous reports that the "in vitro contraction model" can faithfully display one of the most important aspects of the beneficial effects of exercise, i.e. improvement of insulin responsiveness in terms not only of GLUT4 translocation [17] but also of glycogen accumulation.

Since several lines of evidence demonstrated IL-6 to have the ability to increase glucose metabolism as well as insulin actions in skeletal muscles [44, 45], future studies are anticipated to focus on whether the IL-6 released from the contracting myotubes serves as an autocrine factor improving the insulin responsiveness and/or augmented glycogen accumulations observed in EPS-treated cells in this culture system. Finally, given that insulin alone had no impact on IL-6 expression without EPS but tended to potentiate EPS-induced IL-6 up-regulation even under $\mathrm{HG}$ conditions with remarkable increases in glycogen accumulation, IL-6 regulation in response to EPS-evoked contractile activity is apparently dependent on various cellular contexts and is subject to highly complex regulatory mechanisms. While interrelations/cross-talks between insulin-and EPS-induced intracellular signaling cascades have yet to be examined, it is highly likely that insulin stimulation alters EPS-induced IL-6 regulation by modulating these intracellular signals in addition to glycogen accumulation. Further studies will be necessary to resolve this important issue.

\section{Acknowledgement}

The authors thank Fumie Wagatsuma and Natsumi Emoto for their technical assistance. This study was supported by grants from the Ministry of Education, Science, Sports and Culture of Japan (\#22590969 and \#20001007) and the JST A-STEP (AS2321552G). This study was also partially supported by Banyu Life Science Foundation International and Takeda Science Foundation.

\section{References}

1. Pedersen BK, Febbraio MA (2012) Muscles, exercise and obesity: skeletal muscle as a secretory organ. Nat Rev Endocrinol 8: 457-465.

2. Nielsen AR, Pedersen BK (2007) The biological roles of exercise-induced cytokines: IL-6, IL-8, and IL-15. Appl Physiol Nutr Metab 32: 833-839.
3. Croisier JL, Camus G, Venneman I, Deby-Dupont G, Juchmes-Ferir A, Lamy M, Crielaard JM, Deby C, Duchateau J (1999) Effects of training on exercise-induced muscle damage and interleukin 6 production. Muscle Nerve 22: 208-212.

4. Ostrowski K, Rohde T, Zacho M, Asp S, Pedersen 
BK (1998) Evidence that interleukin-6 is produced in human skeletal muscle during prolonged running. $J$ Physiol 508 : 949-953.

5. Jonsdottir IH, Schjerling P, Ostrowski K, Asp S, Richter EA, Pedersen BK (2000) Muscle contractions induce interleukin-6 mRNA production in rat skeletal muscles. J Physiol 528: 157-163.

6. Hiscock N, Chan MH, Bisucci T, Darby IA, Febbraio MA (2004) Skeletal myocytes are a source of interleukin-6 mRNA expression and protein release during contraction: evidence of fiber type specificity. FASEB $J 18$ : 992-994

7. Febbraio MA, Hiscock N, Sacchetti M, Fischer CP, Pedersen BK (2004) Interleukin-6 is a novel factor mediating glucose homeostasis during skeletal muscle contraction. Diabetes 53: 1643-1648.

8. Ruderman NB, Keller C, Richard AM, Saha AK, Luo Z, Xiang X, Giralt M, Ritov VB, Menshikova EV, Kelley DE, Hidalgo J, Pedersen BK, Kelly M (2006) Interleukin-6 regulation of AMP-activated protein kinase. Potential role in the systemic response to exercise and prevention of the metabolic syndrome. Diabetes 55: S48-54.

9. Pedersen BK, Akerstrom TC, Nielsen AR, Fischer CP (2007) Role of myokines in exercise and metabolism. $J$ Appl Physiol 103: 1093-1098.

10. Nehlsen-Cannarella SL, Fagoaga OR, Nieman DC, Henson DA, Butterworth DE, Schmitt RL, Bailey EM, Warren BJ, Utter A, Davis JM (1997) Carbohydrate and the cytokine response to $2.5 \mathrm{~h}$ of running. J Appl Physiol 82: 1662-1667.

11. Nieman DC, Nehlsen-Cannarella SL, Fagoaga OR, Henson DA, Utter A, Davis JM, Williams F, Butterworth DE (1998) Influence of mode and carbohydrate on the cytokine response to heavy exertion. Med Sci Sports Exerc 30: 671-678.

12. Febbraio MA, Steensberg A, Keller C, Starkie RL, Nielsen HB, Krustrup P, Ott P, Secher NH, Pedersen BK (2003) Glucose ingestion attenuates interleukin-6 release from contracting skeletal muscle in humans. $J$ Physiol 549: 607-612.

13. Keller C, Steensberg A, Pilegaard H, Osada T, Saltin B, Pedersen BK, Neufer PD (2001) Transcriptional activation of the IL-6 gene in human contracting skeletal muscle: influence of muscle glycogen content. FASEB J 15 : 2748-2750.

14. Steensberg A, Febbraio MA, Osada T, Schjerling P, van Hall G, Saltin B, Pedersen BK (2001) Interleukin-6 production in contracting human skeletal muscle is influenced by pre-exercise muscle glycogen content. $J$ Physiol 537: 633-639.

15. Keller P, Keller C, Carey AL, Jauffred S, Fischer CP, Steensberg A, Pedersen BK (2003) Interleukin-6 production by contracting human skeletal muscle: autocrine regulation by IL-6. Biochem Biophys Res Commun 310:
550-554.

16. Weigert C, Dufer M, Simon P, Debre E, Runge H, Brodbeck K, Haring HU, Schleicher ED (2007) Upregulation of IL-6 mRNA by IL- 6 in skeletal muscle cells: role of IL-6 mRNA stabilization and Ca2+dependent mechanisms. Am J Physiol Cell Physiol 293: C1139-1147.

17. Nedachi T, Fujita H, Kanzaki M (2008) Contractile C2C12 myotube model for studying exercise-inducible responses in skeletal muscle. Am J Physiol Endocrinol Metab 295: E1191-1204.

18. Nedachi T, Hatakeyama H, Kono T, Sato M, Kanzaki M (2009) Characterization of contraction-inducible CXC chemokines and their roles in $\mathrm{C} 2 \mathrm{C} 12$ myocytes. Am J Physiol Endocrinol Metab 297: E866-878.

19. Yaffe D, Saxel O (1977) Serial passaging and differentiation of myogenic cells isolated from dystrophic mouse muscle. Nature 270: 725-727.

20. Nedachi T, Kanzaki M (2006) Regulation of glucose transporters by insulin and extracellular glucose in C2C12 myotubes. Am J Physiol Endocrinol Metab 291: E817-828.

21. Fujita H, Nedachi T, Kanzaki M (2007) Accelerated de novo sarcomere assembly by electric pulse stimulation in C2C12 myotubes. Exp Cell Res 313: 1853-1865.

22. Kruszynska YT, Ciaraldi TP, Henry RR (2011) Regulation of Glucose Metabolism in Skeletal Muscle. Compr Physiol 2011, Supplement 21: Handbook of Physiology, The Endocrine System, The Endocrine Pancreas and Regulation of Metabolism 579-607.

23. Banzet S, Koulmann N, Simler N, Birot O, Sanchez H, Chapot R, Peinnequin A, Bigard X (2005) Fibre-type specificity of interleukin-6 gene transcription during muscle contraction in rat: association with calcineurin activity. J Physiol 566: 839-847.

24. Burch N, Arnold AS, Item F, Summermatter S, Brochmann Santana Santos G, Christe M, Boutellier U, Toigo M, Handschin C (2010) Electric pulse stimulation of cultured murine muscle cells reproduces gene expression changes of trained mouse muscle. PLoS One 5: e10970.

25. Lambernd S, Taube A, Schober A, Platzbecker B, Gorgens SW, Schlich R, Jeruschke K, Weiss J, Eckardt K, Eckel J (2012) Contractile activity of human skeletal muscle cells prevents insulin resistance by inhibiting pro-inflammatory signalling pathways. Diabetologia 55: 1128-1139.

26. Whitham M, Chan MH, Pal M, Matthews VB, Prelovsek O, Lunke S, El-Osta A, Broenneke H, Alber J, Bruning JC, Wunderlich FT, Lancaster GI, Febbraio MA (2012) Contraction-induced IL-6 gene transcription in skeletal muscle is regulated by c-jun terminal kinase/Activator protein -1. J Biol Chem 287: 10771-10779.

27. Nikolic N, Skaret Bakke S, Tranheim Kase E, Rudberg I, Flo Halle I, Rustan AC, Thoresen GH, Aas V (2012) 
Electrical pulse stimulation of cultured human skeletal muscle cells as an in vitro model of exercise. PLoS One 7, e33203.

28. Banzet S, Koulmann N, Sanchez H, Serrurier B, Peinnequin A, Alonso A, Bigard X (2007) Contractioninduced interleukin-6 transcription in rat slow-type muscle is partly dependent on calcineurin activation. $J$ Cell Physiol 210: 596-601.

29. Allen DL, Uyenishi JJ, Cleary AS, Mehan RS, Lindsay SF, Reed JM (2010) Calcineurin activates interleukin-6 transcription in mouse skeletal muscle in vivo and in C2C12 myotubes in vitro. Am J Physiol Regul Integr Comp Physiol 298: R198-210.

30. Chan MH, McGee SL, Watt MJ, Hargreaves M, Febbraio MA (2004) Altering dietary nutrient intake that reduces glycogen content leads to phosphorylation of nuclear p38 MAP kinase in human skeletal muscle: association with IL-6 gene transcription during contraction. FASEB J 18: 1785-1787.

31. Gallucci S, Provenzano C, Mazzarelli P, Scuderi F, Bartoccioni E (1998) Myoblasts produce IL-6 in response to inflammatory stimuli. Int Immunol 10: 267273.

32. Frost RA, Nystrom GJ, Lang CH (2003) Lipopolysaccharide and proinflammatory cytokines stimulate interleukin-6 expression in $\mathrm{C} 2 \mathrm{C} 12$ myoblasts: role of the Jun NH2-terminal kinase. Am J Physiol Regul Integr Comp Physiol 285: R1153-1164.

33. Frost RA, Nystrom GJ, Lang CH (2006) Multiple Tolllike receptor ligands induce an IL-6 transcriptional response in skeletal myocytes. Am J Physiol Regul Integr Comp Physiol 290: R773-784.

34. Luo G, Hershko DD, Robb BW, Wray CJ, Hasselgren PO (2003) IL-1beta stimulates IL-6 production in cultured skeletal muscle cells through activation of MAP kinase signaling pathway and NF-kappa B. Am J Physiol Regul Integr Comp Physiol 284: R1249-1254.

35. Kosmidou I, Vassilakopoulos T, Xagorari A, Zakynthinos S, Papapetropoulos A, Roussos C (2002) Production of interleukin- 6 by skeletal myotubes: role of reactive oxygen species. Am J Respir Cell Mol Biol 26: 587-593.

36. Frost RA, Nystrom GJ, Lang CH (2004) Epinephrine stimulates IL-6 expression in skeletal muscle and C2C12 myoblasts: role of c-Jun NH2-terminal kinase and histone deacetylase activity. Am J Physiol Endocrinol Metab 286: E809-817.

37. Owens DM, Keyse SM (2007) Differential regulation of MAP kinase signalling by dual-specificity protein phosphatases. Oncogene 26: 3203-3213.

38. Coyle EF, Coggan AR, Hemmert MK, Ivy JL (1986) Muscle glycogen utilization during prolonged strenuous exercise when fed carbohydrate. J Appl Physiol 61: 165-172.

39. Goodyear LJ, Hirshman MF, Valyou PM, Horton ES (1992) Glucose transporter number, function, and subcellular distribution in rat skeletal muscle after exercise training. Diabetes 41: 1091-1099.

40. Ivy JL, Kuo CH (1998) Regulation of GLUT4 protein and glycogen synthase during muscle glycogen synthesis after exercise. Acta Physiol Scand 162: 295-304.

41. Franch J, Aslesen R, Jensen J (1999) Regulation of glycogen synthesis in rat skeletal muscle after glycogendepleting contractile activity: effects of adrenaline on glycogen synthesis and activation of glycogen synthase and glycogen phosphorylase. Biochem J 344: 231-235.

42. Nedachi T, Kadotani A, Ariga M, Katagiri H, Kanzaki M (2008) Ambient Glucose Levels Qualify the Potency of Insulin Myogenic Actions by Regulating SIRT1 and FoxO3a in C2C12 myocytes. Am J Physiol Endocrinol Metab 294: E668-678.

43. Bouskila M, Hunter RW, Ibrahim AF, Delattre L, Peggie M, van Diepen JA, Voshol PJ, Jensen J, Sakamoto K (2010) Allosteric regulation of glycogen synthase controls glycogen synthesis in muscle. Cell Metab 12: 456466.

44. Weigert C, Hennige AM, Brodbeck K, Haring HU, Schleicher ED (2005) Interleukin-6 acts as insulin sensitizer on glycogen synthesis in human skeletal muscle cells by phosphorylation of Ser473 of Akt. Am J Physiol Endocrinol Metab 289: E251-257.

45. Glund S, Deshmukh A, Long YC, Moller T, Koistinen HA, Caidahl K, Zierath JR, Krook A (2007) Interleukin-6 directly increases glucose metabolism in resting human skeletal muscle. Diabetes 56: 1630-1637. 